\title{
A Sociologia do Turismo na Educação Superior em Portugal
}

\section{The Sociology of Tourism in College Education in Portugal}

\author{
Noemi Marujo (MARUJO, N.) ${ }^{*}$
}

\begin{abstract}
RESUMO - O turismo exerce, cada vez mais, um papel socializador dentro de uma sociedade. Ele permite o encontro entre seres humanos de distintas culturas e contribui, em muitos casos, para as mudanças sociais e culturais de uma região ou país. Se a sociologia é a ciência que estuda os factos sociais ou a ação social, então, o turismo pode ser entendido como um fenómeno social, onde a sociologia do turismo tem como objeto de estudo a natureza da interação entre turistas e residentes e também a análise dos impactos sociais e culturais onde o turismo se desenvolve. O presente artigo pretende analisar a importância da Sociologia do Turismo na estrutura dos planos curriculares dos cursos superiores de turismo e/ou suas áreas afins (hotelaria, ecoturismo, animação, dentre outras) nas instituições de ensino superior em Portugal. $\mathrm{O}$ estudo teve como principal enfoque os primeiros Ciclos de Estudo que oferecem a Sociologia do Turismo como unidade curricular obrigatória.
\end{abstract}

Palavras-chave: Sociologia; Turismo; Educação Superior.

ABSTRACT - The tourism has a socializing role in the society. Tourism allows the meeting of people from different cultures and contributes, in many cases, for the social and cultural changes in a region or country. If sociology is the science that studies the social facts or social action, then, tourism can be understood as a social phenomenon, so the sociology of tourism has as object of study the nature of the interaction between tourists and residents, and it also analyzes the social and cultural impacts where tourism develops. This paper aims to analyze the importance of the Sociology of Tourism in the structure of the college courses of tourism or its related areas (hotels, ecotourism, animation,) in the institutions of higher education in Portugal. The study had as main focus the tourism courses that offer the Sociology of Tourism as an obligatory subject in the curriculum.

Key words: Sociology; Tourism; College Education.

\footnotetext{
* Licenciatura em Comunicação Social (UBI). Mestrado em Sociologia (Universidade de Évora). Doutorado em Turismo (Universidade de Évora). DEA em Turismo, Lazer e Cultura - Ramo Turismo e Desenvolvimento (Universidade de Coimbra). Professora Auxiliar na Universidade de Évora/Professora Coordenadora na Licenciatura em Turismo do ISCE. Investigadora do IGOT-CEG-TERRITUR (Turismo, Cultura e Território). Endereço para correspondência: Departamento de Sociologia da Universidade de Évora. Largo dos Colegiais, N. 2 - 7004-516 - Évora - Portugal. E-mail: noemi@uevora.pt
} 


\section{INTRODUÇÃO ${ }^{1}$}

O turismo dentro de uma sociedade exerce um papel socializador, pois ele permite o encontro entre pessoas de diferentes culturas, diminui as distâncias étnicas ao permitir um maior conhecimento dos outros e dos seus costumes, e contribui para uma maior compreensão entre as mais distintas populações.

O turismo é um fenómeno social, político, cultural, económico e ambiental e, por isso, diversas disciplinas científicas têm vindo a elegê-lo como objeto privilegiado de investigação. De facto, a interdisciplinaridade ou multidisciplinaridade do turismo encaminha para definições e explicações que envolvem a Psicologia, a Geografia, a Economia, a Antropologia, a História e a Sociologia. As diversas ciências incorporam o fenómeno turístico dentro do seu contexto para, depois, explicá-lo de acordo com os seus instrumentos metodológicos e visões teóricas (MARUJO, 2005).

O turismo é, na sociedade contemporânea, uma atividade com um significado indiscutível. O extraordinário desenvolvimento deste fenómeno deu origem a um crescimento concomitante nos estudos académicos e no conhecimento do turismo (TRIBE, 2010). Em Portugal, as características da interdisciplinaridade e multidisciplinaridade têm marcado fortemente a forma como os cursos de turismo são estruturados, bem como os tipos de pesquisa que são realizados. A aplicação da multidisciplinaridade e da interdisciplinaridade nos estudos do turismo é determinada, em muitos casos, pela formação dos investigadores, mas também pelos conhecimentos e metodologia das diferentes disciplinas que eles utilizam na sua pesquisa. De facto, a abrangência e complexidade da atividade turística leva muitos dos investigadores a recorrerem ao auxílio de mais do que uma disciplina para as suas pesquisas o que remete para o campo da interdisciplinaridade. "A interdisciplinaridade, fundamental à análise do turismo como fenómeno social, cultural, comunicacional, económico e subjetivo, ultrapassa as fronteiras de uma única disciplina ou de um único campo do saber" (MOESCH, 2002, p. 14).

A visão sociológica é insuficiente para compreender em toda a sua profundidade a riqueza e a diversidade do fenómeno turístico. No entanto, ela tem dado e continua a dar um contributo fundamental para a análise das práticas turísticas. O papel da

\footnotetext{
${ }^{1}$ Publicado no idioma português de Portugal.
} 
sociologia nos estudos do turismo "é uma evidência que não precisa de justificação adicional" (MARUJO, 2005, p. 21). Se o turismo é um fenómeno social, e se a sociologia estuda a realidade social ou as mudanças produzidas nas diferentes sociedades, então, que importância assume a sociologia do turismo nos cursos superiores de turismo em Portugal? O presente artigo pretende analisar a importância da Sociologia do Turismo na estrutura dos planos curriculares dos cursos superiores de turismo e/ou suas áreas afins (hotelaria, ecoturismo, animação, dentre outras) nas instituições de ensino superior em Portugal. O estudo teve como principal enfoque os primeiros Ciclos de Estudo (Licenciaturas) que oferecem a Sociologia do Turismo como unidade curricular obrigatória.

\section{A SOCIOLOGIA E O TURISMO}

O turismo é um acontecimento social total que pode produzir grandes mudanças estruturais numa sociedade, num país ou numa região (LICKORISH; JENKINS, 2000). A sociologia, através dos seus métodos de investigação, procura compreender e analisar as estruturas em diversas sociedades. Entendida como o estudo da vida social humana, dos grupos e sociedades (GIDDENS, 2010), e tendo como objeto de estudo os 'factos sociais' (DURKHEIM, 1990) ou a 'ação social' (WEBER, 1991), a sociologia assume na atualidade um papel fundamental na pesquisa em turismo.

A sociologia foi uma disciplina chave na emergência do estudo académico sobre o turismo (FRANKLIN, 2009).

\footnotetext{
A relação entre a sociologia e o turismo é evidente, pois é um facto bem conhecido que o turismo como uma prática social e uma representação, bem como um sistema de ação e tomada de decisão, está a tornar-se uma dinâmica cada vez mais importante nas sociedades contemporâneas (LANFANT, 1993, p. 70).
}

O turismo é uma atividade que se realiza em sociedade (DAMIÁN, 2009) e, portanto, "a sociologia capta o turismo como um fator de desenvolvimento no âmbito económico e sociocultural, observando junto com outras ciências sociais, a incidência que este fenómeno exerce nas sociedades" (ANDRADE, 2010, p. 90). De facto, a sociologia detém um grande campo de intervenção no campo do turismo dado que ele é 
um fenómeno social moderno (MAZÓN, 2001) que tem interferência em diversos temas como, por exemplo, no estilo de vida de uma comunidade, na cultura e no encontro entre sociedades diferentes.

No campo da sociologia, o fenómeno turístico tem interesse por vários motivos: provoca mudanças no comportamento dos indivíduos e agrega conhecimento àqueles que o praticam; causa forte impacto nas pessoas e grupos familiares que se deslocam para distintos lugares; permite comparação entre diferentes culturas, contribui para o fortalecimento da identidade grupal; contribui para a formação e educação daqueles que praticam turismo; é um meio de difusão de novas práticas sociais (DIAS, 2003).

A sociologia teve e tem um particular interesse sobre as interações que ocorrem entre os visitantes e residentes, principalmente quando estes têm diferentes valores, expectativas e comportamentos padrão que podem ser expressos ou não em normas sociais (JAFARI; RITCHIE, 1981). Para além do interesse da sociologia pela interação social entre turistas e anfitriões, outros estudos importantes recaem sobre as manifestações das relações de poder, hierarquia, funções, papéis, níveis e classes nas possíveis estruturas das viagens em grupo ou individuais (ASCANIO, 1992).

\footnotetext{
Independentemente do turismo ser considerado ou tratado como uma hospitalidade mercantilizada, uma viagem democratizada ou atividade de lazer moderna $[\ldots]$ continua sendo um fenómeno sociocultural, político e económico complexo que requer uma investigação sociológica sistemática (APOSTOLOPOULOS, 2001, p. 4).
}

Dann (2005) argumenta que o tratamento sociológico do turismo tem, provavelmente, contribuído mais para o estado atual do conhecimento do turismo como um fenómeno social do que qualquer outra disciplina. Uma das razões pelas quais a sociologia demonstrou ser valiosa para o estudo do turismo prende-se, essencialmente, pelo "seu interesse em saber como e por que o turismo surge na sociedade moderna e como as suas várias interações se relacionam e podem ser explicadas pelas mudanças sociais nos séculos XIX e XX" (FRANKLIN, 2009, p. 66). Para este autor, a sociologia procura saber como o turismo se relaciona com sociedades específicas, contextos e culturas, e como as mudanças sociais e culturais mudam a sua expressão e o seu impacto. Todavia, não existe uma perspetiva sociológica única que reclame para si o monopólio da compreensão do fenómeno turístico, uma vez que o turismo é um 
fenómeno multidimensional sobre o qual se aplicam diversas aproximações teóricas (DANN; COHEN, 2001). Assim sendo:

[...] A Sociologia apresenta apenas uma interpretação parcial do fenómeno multifacetado do turismo. Para um quadro mais completo, é necessário combinar os resultados obtidos com aqueles que foram conseguidos em outras disciplinas do campo das ciências sociais (DIAS, 2003, p. 18).

Os primeiros estudos da aproximação da sociologia com o turismo surgiram com o italiano Luigi Bodio ${ }^{2}$ que, em 1899, publicou o primeiro artigo científico com conteúdo social intitulado "Sul movimento dei foresteri in Italia e sul dinero chi vi spendono" (COHEN, 1984). Mas, as maiores contribuições surgiram na Alemanha por volta de 1920. "De facto, o estudo sociológico do fenómeno turístico inicia-se através do que Hans-Joachim Knebel denominou 'sociologia da ciência do movimento de forasteiros', pelos anos 20 do século passado" (GIL; LUCAS; CUEVAS, 2003, p. 18). A partir daqui, e segundo os autores, desenvolveram-se várias pesquisas com a necessidade de compreender o turismo desde uma perspetiva sociológica, tais como: as relações interpessoais de George Simmel ${ }^{3}$, em 1923, e Leopold Von Wiese ${ }^{4}$, em 1930; as viagens das pessoas de Arthur Bormann ${ }^{5}$, em 1931, e os estudos de Willi Benscheidt $^{6}$, em 1933, relacionados com as motivações da viagem (GIL; LUCAS; CUEVAS, 2003). Porém, o primeiro estudo especificamente sociológico sobre turismo surgiu, em 1960, com o trabalho "Soziologische Strukturwandlungen in Modernen Tourismus", realizado por Hans-Joachim Knebel ${ }^{7}$, que "investigava pela primeira vez o turismo em função da mudança social" (MUELA, 2003, p. 44). Segundo este autor, a contribuição da sociologia do turismo de Hans-Joachim Knebel está relacionada

${ }^{2}$ BODIO, L. Sul movimento dei foresteri in Italia e sul dinero chi vi spendono. Giornale Degli Economisti, n. 15, p. 54-61, 1899.

${ }^{3}$ SIMMEL, G. Exkurs über den Fremden. In: George Simmel (3. Ed.), Soziologie: Untersuchungen über die Formen der Vergesellschaftung. Berlin: Duncker \& Humblot, p. 509-512, 1928.

${ }^{4}$ WIESE, L. Fremdenverkehr als zwischenmenschliche Beziehungen. Archiv für den Fremdenverkehr. n.1, p. 1-3, 1930.

5 BORMMAN, A. Die Lehre vom Fremdenverkehr. Berlin: Verkehrswissenschaftliche Lehrmittelgesellschaft, 1931.

${ }^{6}$ BENSCHEIDT, W. Der Ortswechsel als Voraussetzung des Fremdenverkehrs. Archiv für den Fremdenverkehr. n. 3, 1933.

${ }^{7}$ KNEBEL, H-J. Soziologische Strukturwandlungen in Modernen Tourismus. Stuttgart: Enke, 1960. 
especialmente com a mudança social que o turismo pode provocar nas sociedades. Para ele, o ponto de partida para o estudo do fenómeno turístico é o turista e há quatro critérios que o caracterizam: a existência ou inexistência de inter-relações entre turistas e residentes; a necessidade de conforto e segurança física; a necessidade de mobilidade; a satisfação do consumo de necessidades de luxo no destino (DIAS, 2003).

Os estudos sociológicos do turismo ocorreram com mais intensidade, por volta dos anos 70 do século passado, com as tipologias de Erik Cohen onde o autor apresenta um modelo baseado nas experiências turísticas e nos papéis: o turista de massa organizado; o turista de massa individual; o explorador e o nômade (COHEN, 1972). Para este sociólogo, o turismo provoca alguns efeitos sociais sobre a sociedade recetora. “À medida que o papel do turista se torna institucionalizado, um conjunto de outros papéis e instituições desenvolve-se na comunidade anfitriã para atender às suas necessidades" (COHEN, 1972, p. 178). Outro autor que contribuiu nesta época para a investigação sociológica em turismo foi Dean MacCannell ${ }^{8}$, em 1973, com as primeiras sínteses teóricas sobre a questão da autenticidade encenada nos cenários turísticos. $\mathrm{O}$ autor mostrou-se especialmente interessado no carácter das relações sociais que surgem a partir do fascínio que as pessoas demonstram pela vida quotidiana dos outros, e argumentava que essas vidas reais apresentavam-se aos turistas como uma 'autenticidade encenada' (MACCANNELL, 2003). A partir de meados dos anos 70 do século passado, e nos países desenvolvidos, a abordagem sociológica do turismo cresceu de uma forma muito rápida, o que pode ser confirmado com a publicação de uma série de livros e artigos em diversas revistas (COHEN, 2001). Nesta época, houve também uma preocupação dos sociólogos em desenvolver um modelo geral para o desenvolvimento do turismo num destino e, também, um esforço para compreender as relações entre os turistas e anfitriões (COHEN, 1979).

Nos anos 80 do século passado, e apesar de se terem realizado muitas investigações sobre a atividade turística, o estudo do turismo não se integrou totalmente na sociologia académica (MUELA, 2003). Todavia, alguns autores contribuíram para o desenvolvimento dos estudos como, por exemplo, Erik Cohen, que no seu artigo "The Sociology of Tourism: Approaches, Issues and Findings", publicado em 1984, na Revista "Annual Review of Sociology", apresentou quatro áreas de estudo relacionadas

${ }^{8}$ MACCANNELL, D. Staged authenticity: arrangements of social space in tourist settings. The American Journal of Sociology, v. 79, n. 3, p. 589-603, 1973. 
com a sociologia do turismo: "o turista (as suas motivações, atitudes, reações e papéis); as relações e perceções dos turistas e moradores; a estrutura do sistema turístico; os impactos socioculturais e socioeconómicos do turismo" (COHEN, 1984, p. 373). Sublinhe-se, também, a obra de Robert Lanquar "Sociologie du tourisme et des voyages", publicada em 1985, em que o autor afirma que a natureza complexa do fenómeno turístico converte a sociologia do turismo num campo com várias dimensões como, por exemplo, o bem-estar e o quadro da vida, a cultura e a comunicação, os grupos sociais, o desenvolvimento, o encontro de sociedades diferentes, a psicologia dos indivíduos, os estudos de impacto ou de mercado e a gestão do tempo de trabalho (LANQUAR, 1985).

Nos anos 90, as tendências da sociologia do turismo tomaram outra dimensão. Nesta época, um dos primeiros autores a atribuir uma modificação ao modelo de investigação tradicional na sociologia do turismo foi John Urry que, na sua monografia "The Tourist Gaze. Leisure and Travel in Contemporary Societies", publicada em $1990^{9}$, se preocupou, para além dos estudos tradicionais sobre o impacto nas sociedades recetoras do turismo, com o comportamento do turista. A análise deste sociólogo centrase especialmente no processo do 'olhar' do turista em, que segundo ele, “não existe um único olhar do turista enquanto tal. Ele varia de acordo com a sociedade, o grupo social e o período histórico. Tais olhares são construídos por meio da diferença" (URRY, 1996, p. 16).

Nos últimos anos, e no campo do turismo, os estudos sociológicos têm dedicado a sua atenção às questões da mobilidade e às influências das tecnologias de informação e comunicação, nomeadamente à análise do turismo no ciberespaço. "A nova sociologia do turismo analisa, em termos gerais, os padrões de consumo, as mudanças na hierarquia social e representações visuais projetadas através dos meios de comunicação" (SMITH; MACLEOD; ROBERTSON, 2010, p. 158).

Após esta análise sobre os percursos da investigação sociológica no campo do turismo, é possível verificar que a pesquisa passou por diferentes tendências, mas que estão “[...] um pouco alheias das realidades sociais que apresenta a atividade turística internacional” (MUELA, 2003, p. 69). Pode-se concluir que a sociologia vai progressivamente incorporando o turismo, em algumas das suas dimensões, como

${ }^{9}$ URRY, J. The Tourist Gaze. Leisure and Travel in Contemporary Societies. London: Sage Publications, 1990. 
objeto de estudo indispensável para a compreensão das mudanças sociais que ocorrem globalmente ou localmente na sociedade de informação e do conhecimento (MARUJO, 2005).

\subsection{A SOCIOLOGIA DO TURISMO COMO OBJETO DE ESTUDO}

Alguns autores consideram que a Sociologia do Turismo é uma disciplina social e científica jovem (HUETE, 2007; ANDRADE, 2010). No entanto, ela tem sido uma especialidade com algum progresso na pesquisa turística. A crescente atenção dada à cultura das sociedades, às diversas imagens e significados transmitidos pelos diferentes destinos, às rápidas mudanças da atividade turística (URRY; LARSEN, 2011) e às relações sociais que se estabelecem entre os turistas e anfitriões têm, de certa forma, contribuído para uma maior aplicação da sociologia do turismo na investigação turística.

Para Lanquar (1985), a sociologia do turismo está em formação através de um processo de integração e diferenciação, e procura integrar as suas contribuições num sistema simultaneamente sincrónico e diacrónico onde enuncia alguns princípios gerais sobre o comportamento dos atores turísticos, bem como os efeitos sobre as sociedades onde o fenómeno se desenvolve. Segundo este sociólogo, “o objeto de estudo da sociologia do turismo e das viagens não se pode afirmar numa definição, mas sim pela ação crítica e por uma análise direta de correspondência entre a realidade social do turismo e das viagens e os conceitos da sociologia" (LANQUAR, 1985, p. 8).

Segundo Cohen (1979), não existe uma sociologia do turismo como campo separado da teorização sociológica. O que existe é "[...] a aplicação de teorias sociológicas gerais ao campo específico do turismo" (COHEN, 1979, p. 31). Assim sendo, a sociologia do turismo é uma especialidade interessada no estudo das motivações turísticas, nos papéis e relações sociais dos turistas, na natureza das atrações e das suas representações, e no impacto do turismo nas sociedades recetoras (COHEN, 1979). O autor define uma estratégia de investigação para a sociologia do turismo, onde sugere que ela deve ser: processual (levar em conta os impactos do turismo); contextual (considerar a circunstância política e ecológica do estudo); comparativa (realizar uma análise das várias situações turísticas); 'emic' (considerar a perspetiva dos vários atores no processo turístico). A estratégia de investigação proposta pelo autor visa cortar 
caminho entre uma presunçosa tentativa de criar uma monolítica 'teoria do turismo' e uma investigação fragmentária de discretos problemas empíricos.

\begin{abstract}
Embora reconhecendo que o turismo não é um sub-campo da sociologia, e que muitas e diversas abordagens podem ser aplicadas na sua investigação deve-se, no entanto, procurar estabelecer um estilo comum de investigação através do qual a continuidade da pesquisa e a generalização das descobertas será facilitada (COHEN, 1979, p. 32).
\end{abstract}

A sociologia do turismo é definida por Knebel ${ }^{10}$, como "a ciência que estuda o comportamento social do homem, que transforma durante as férias o seu papel social, deixando para trás os diferentes papéis que desempenha (profissional, económico e social) e assumindo o papel de turista" (DIAS, 2003, p. 18-19). Fuster (1974) afirma também que a sociologia do turismo deve estudar as relações e os fenómenos causados pela presença do turista num determinado núcleo recetor. "Nisso residiria a aplicação central da sociologia como teoria de génese turística, cabendo-lhe ainda um papel importante, o pedagógico: aconselhar os visitantes sobre as idiossincrasias dos visitados" (MOESCH, 2002, p. 22).

Se a sociologia é a ciência que estuda os fenómenos sociais e as mudanças produzidas na sociedade, então o turismo pode ser compreendido como um fenómeno social, onde a sociologia do turismo se dedica "a estudar o turismo nos seus aspetos sociais" (DIAS, 2003, p. 11). Ou seja, "a sociologia do turismo apresenta teorias e pesquisas sobre os fenómenos sociais" (HUETE, 2007, p. 84). Assim sendo, a sociologia do turismo e o seu objeto sociológico devem capturar a multi-pluralidade do turismo como um fenómeno social (LANFANT, 1993).

\title{
3 A SOCIOLOGIA DO TURISMO NA EDUCAÇÃO SUPERIOR EM PORTUGAL
}

Como já foi referido, o presente artigo analisa a importância da Sociologia do Turismo na estrutura dos planos curriculares dos cursos superiores de turismo e/ou suas áreas afins (hotelaria, ecoturismo, animação, dentre outras) nas instituições de ensino

${ }^{10}$ KNEBEL, Hans-Joachim. Sociología del turismo: cambios estructurales en el turismo moderno. Barcelona: Hispano-Europea, 1974. 
superior em Portugal. O estudo teve como principal enfoque os primeiros Ciclos de Estudo (Licenciaturas) que oferecem a 'Sociologia do Turismo' como unidade curricular obrigatória.

Para circunscrever a simplificação da temática em estudo e obter uma maior familiarização com o tema, optou-se por realizar uma pesquisa exploratória. Sublinhe-se que a pesquisa exploratória pretende proporcionar uma visão geral sobre um determinado facto, sobretudo, quando existe pouca informação ou dados sobre o fenómeno a ser estudado (JENNINGS, 2010). Assim, e com o intuito de concretizar o objetivo do presente estudo, consultou-se os Cursos Superiores de Turismo e/ou suas áreas afins em funcionamento, no ano letivo 2012/2013, nas diversas instituições de ensino superior públicas e privadas e, também, o Site da Direção Geral do Ensino Superior (DGES $)^{11}$. Através do Site da DGES, foi possível averiguar o nome do estabelecimento de ensino e do curso em funcionamento. A consulta aos planos curriculares, através, das diferentes instituições do ensino superior permitiu apurar a existência ou não da 'Sociologia do Turismo'. Seguidamente elaborou-se as seguintes grelhas de análise (Quadro I e II), que certificam a existência ou inexistência da disciplina 'Sociologia do Turismo' como unidade curricular obrigatória nas diferentes licenciaturas na área do turismo.

Refira-se que para a análise e tratamento da informação recolhida, recorreu-se ao método da análise de conteúdo descritiva. A análise de conteúdo pode ser entendida como uma ferramenta científica que fornece novas visões, aumenta a compreensão do investigador sobre os fenómenos particulares ou informa sobre ações práticas (KRIPPENDORF, 2004).

QUADRO I - CURSOS SUPERIORES DE TURISMO (LICENCIATURAS) NAS INSTITUIÇÕES PÚBLICAS EM PORTUGAL

\begin{tabular}{|c|c|c|}
\hline Instituição & Curso & $\begin{array}{c}\text { Designação da Unidade } \\
\text { Curricular Obrigatória }\end{array}$ \\
\hline Universidade do Algarve - Escola & & $\bullet$ Sociologia do Turismo \\
\cline { 2 - 3 } Superior de Gestão, Hotelaria e Turismo & Turismo & $\mathrm{X}$ \\
\cline { 2 - 3 } & $\begin{array}{c}\text { Informação Hoteleira } \text { Animação } \\
\text { Turística }\end{array}$ & X Sociologia e Metodologia \\
& Turismo & \begin{tabular}{c} 
em Turismo \\
\hline
\end{tabular} \\
\hline
\end{tabular}

Continua...

11 <http://www.dges.mctes.pt/DGES/pt/OfertaFormativa/ >. Acesso em: 15/09/2012. 
Continuação...

\begin{tabular}{|c|c|c|c|}
\hline Universidade de Coimbra & \multicolumn{2}{|c|}{ Turismo, Lazer e Património } & $\mathrm{X}$ \\
\hline Universidade dos Açores & \multicolumn{2}{|c|}{ Turismo } & $\mathrm{X}$ \\
\hline Universidade de Évora & \multicolumn{2}{|c|}{ Turismo } & $\begin{array}{l}\text { - Sociologia do Lazer e do } \\
\text { Turismo }\end{array}$ \\
\hline $\begin{array}{c}\text { Universidade de Trás-os-Montes e Alto } \\
\text { Douro }\end{array}$ & \multicolumn{2}{|c|}{ Turismo } & $\begin{array}{l}\rightarrow \text { Antropologia e } \\
\text { Sociologia do Turismo }\end{array}$ \\
\hline \multirow{5}{*}{$\begin{array}{l}\text { Escola Superior de Hotelaria e Turismo } \\
\text { do Estoril }\end{array}$} & \multicolumn{2}{|c|}{ Direção e Gestão Hoteleira } & - Sociologia do Turismo \\
\hline & \multicolumn{2}{|c|}{$\begin{array}{c}\text { Gestão do Lazer e Animação } \\
\text { Turística }\end{array}$} & $\mathrm{X}$ \\
\hline & \multicolumn{2}{|c|}{ Informação Turística } & - Sociologia do Turismo \\
\hline & \multirow[t]{2}{*}{$\begin{array}{l}\text { Gestão } \\
\text { Turística }\end{array}$} & $\begin{array}{l}\text { Ramo } \\
\text { Gestão de } \\
\text { Empresas } \\
\text { Turísticas }\end{array}$ & • Sociologia do Turismo \\
\hline & & $\begin{array}{l}\text { Ramo } \\
\text { Gestão de } \\
\text { Produtos } \\
\text { Turísticos }\end{array}$ & - Sociologia do Turismo \\
\hline \multirow{4}{*}{$\begin{array}{c}\text { Instituto Politécnico de Leiria - Escola } \\
\text { Superior de Turismo e Tecnologia do } \\
\text { Mar de Peniche }\end{array}$} & \multicolumn{2}{|c|}{ Animação Turística } & $\mathrm{X}$ \\
\hline & \multicolumn{2}{|c|}{ Turismo } & - Sociologia do Turismo \\
\hline & \multicolumn{2}{|c|}{ Gestão Turística e Hoteleira } & $\mathrm{X}$ \\
\hline & \multicolumn{2}{|c|}{ Marketing Turístico } & $\mathrm{X}$ \\
\hline Instituto Politécnico de Tomar & \multicolumn{2}{|c|}{ Gestão Turística Cultural } & $\begin{array}{l}\text { Economia e Sociologia } \\
\text { do Turismo }\end{array}$ \\
\hline $\begin{array}{c}\text { Instituto Politécnico de Coimbra - } \\
\text { ESEC }\end{array}$ & \multicolumn{2}{|c|}{ Turismo } & $\begin{array}{l}\text { - Sociologia do Lazer e do } \\
\text { Turismo }\end{array}$ \\
\hline $\begin{array}{c}\text { Instituto Politécnico de Coimbra - } \\
\text { ESAC }\end{array}$ & \multicolumn{2}{|c|}{ Ecoturismo } & $\mathrm{X}$ \\
\hline $\begin{array}{c}\text { Instituto Politécnico de Viseu - Escola } \\
\text { Superior de Tecnologia e Gestão de } \\
\text { Viseu }\end{array}$ & \multicolumn{2}{|c|}{ Turismo } & • Sociologia do Turismo \\
\hline \multirow{2}{*}{$\begin{array}{l}\text { Instituto Politécnico de Viseu - Escola } \\
\text { Superior de Tecnologia e Gestão de } \\
\text { Lamego }\end{array}$} & \multicolumn{2}{|c|}{$\begin{array}{c}\text { Gestão Turística Cultural e } \\
\text { Patrimonial }\end{array}$} & • Sociologia do Turismo \\
\hline & \multicolumn{2}{|c|}{ Informação Turística } & - Sociologia do Turismo \\
\hline \multirow{3}{*}{$\begin{array}{c}\text { Instituto Politécnico da Guarda - Escola } \\
\text { Superior de Turismo e Hotelaria }\end{array}$} & \multicolumn{2}{|c|}{ Turismo e Lazer } & $\mathrm{X}$ \\
\hline & \multicolumn{2}{|c|}{ Gestão Hoteleira } & $\begin{array}{l}\text { Sociologia do Lazer e do } \\
\text { Turismo }\end{array}$ \\
\hline & \multicolumn{2}{|c|}{ Informática para o Turismo } & $\mathrm{X}$ \\
\hline Instituto Politécnico de Portalegre & \multicolumn{2}{|c|}{ Turismo } & $\mathrm{X}$ \\
\hline Instituto Politécnico de Beja-ESTIG & \multicolumn{2}{|c|}{ Turismo } & - Sociologia do Turismo \\
\hline Instituto Politécnico do Porto - ESEIG & \multicolumn{2}{|c|}{$\begin{array}{c}\text { Gestão e Administração } \\
\text { Hoteleira }\end{array}$} & $\mathrm{X}$ \\
\hline Instituto Politécnico do Porto - ISCAP & \multicolumn{2}{|c|}{$\begin{array}{c}\text { Gestão das Actividades } \\
\text { Turísticas }\end{array}$} & $\mathrm{X}$ \\
\hline $\begin{array}{c}\text { Instituto Politécnico do Cávado e do } \\
\text { Ave }\end{array}$ & \multicolumn{2}{|c|}{$\begin{array}{l}\text { Gestão de Actividades } \\
\text { Turísticas }\end{array}$} & $\mathrm{X}$ \\
\hline \multirow[t]{2}{*}{ Instituto Politécnico de Bragança } & \multicolumn{2}{|c|}{ Turismo } & $\mathrm{X}$ \\
\hline & Guia & prete & $\begin{array}{l}\text { Economia e Sociologia } \\
\text { do Turismo } \\
\end{array}$ \\
\hline Instituto Politécnico de Castelo Branco & Gestã & eleira & - Sociologia do Turismo \\
\hline $\begin{array}{c}\text { - Escola Superior de Gestão de Idanha- } \\
\text { a-Nova }\end{array}$ & Gestâ & ística & - Sociologia do Turismo \\
\hline
\end{tabular}

Continua... 
Continuação...

\begin{tabular}{|c|c|c|}
\hline Instituto Politécnico de Viana do & Turismo & $\mathrm{X}$ \\
Castelo & & $\mathrm{X}$ \\
\hline Instituto Politécnico de Santarém - & Desporto de Natureza e \\
Escola Superior de Desporto de Rio & Turismo Activo \\
Maior & & Total: $\mathbf{1 9}$ \\
\hline Total: $\mathbf{2 3}$ & Total: $\mathbf{3 6}$ & \\
\hline
\end{tabular}

Fonte: Elaboração Própria (Baseado na DGES, 2012).

$\mathrm{Na}$ análise ao quadro (I), e dos 36 Cursos de Turismo e/ou Hotelaria em funcionamento nas instituições públicas de ensino superior, verificou-se que a 'Sociologia do Turismo' funciona como disciplina obrigatória em 19 cursos. Sublinhese, no entanto, que a 'Sociologia do Turismo' aparece de forma exclusiva em apenas 12 cursos. Em alguns cursos, ela surge associada ao lazer, à economia, à antropologia e à metodologia.

QUADRO II - CURSOS SUPERIORES DE TURISMO (LICENCIATURAS) NAS INSTITUIÇÕES PRIVADAS EM PORTUGAL

\begin{tabular}{|c|c|c|c|}
\hline Instituição & \multicolumn{2}{|c|}{ Curso } & $\begin{array}{l}\text { Designação da Unidade } \\
\text { Curricular Obrigatória }\end{array}$ \\
\hline Universidade Católica de Braga & \multicolumn{2}{|c|}{ Turismo } & $\mathrm{X}$ \\
\hline Universidade Lusíada & \multicolumn{2}{|c|}{ Turismo } & - Sociologia do Turismo \\
\hline $\begin{array}{c}\text { Universidade Lusófona de Humanidades e } \\
\text { Tecnologias - Lisboa }\end{array}$ & \multicolumn{2}{|c|}{ Turismo } & $\begin{array}{l}\text { - Sociologia e Antropologia } \\
\text { do Turismo } \\
\end{array}$ \\
\hline Universidade Lusófona do Porto & \multicolumn{2}{|c|}{$\begin{array}{l}\text { Turismo e Gestão de } \\
\text { Empresas Turísticas }\end{array}$} & $\begin{array}{l}\text { - Sociologia e Antropologia } \\
\text { do Turismo }\end{array}$ \\
\hline $\begin{array}{c}\text { Universidade Portucalense Infante D. } \\
\text { Henrique }\end{array}$ & \multicolumn{2}{|c|}{ Turismo } & - Sociologia do Turismo \\
\hline \multirow[t]{2}{*}{ Instituto Superior D. Afonso III } & \multicolumn{2}{|c|}{ Gestão Turística } & - Sociologia do Turismo \\
\hline & \multicolumn{2}{|c|}{ Turismo Sustentável } & - Sociologia do Turismo \\
\hline Instituto Superior da Maia & \multicolumn{2}{|c|}{ Turismo } & - Sociologia do Turismo \\
\hline \multirow[t]{2}{*}{ Instituto Superior de Novas Profissões } & \multirow[t]{2}{*}{ Turismo } & $\begin{array}{l}\text { Informação } \\
\text { Turística }\end{array}$ & $\begin{array}{l}\text { Sociologia do Lazer e do } \\
\text { Turismo }\end{array}$ \\
\hline & & $\begin{array}{c}\text { Gestão } \\
\text { Hoteleira } \\
\end{array}$ & $\begin{array}{l}\text { - Sociologia do Lazer e do } \\
\text { Turismo }\end{array}$ \\
\hline \multirow{2}{*}{$\begin{array}{c}\text { Instituto Superior de Administração e } \\
\text { Línguas }\end{array}$} & \multicolumn{2}{|c|}{ Turismo } & $\mathrm{X}$ \\
\hline & \multicolumn{2}{|c|}{$\begin{array}{c}\text { Organização e Gestão } \\
\text { Hoteleira }\end{array}$} & $\mathrm{X}$ \\
\hline Instituto Superior de Ciências Educativas & \multicolumn{2}{|c|}{ Turismo } & $\mathrm{X}$ \\
\hline $\begin{array}{l}\text { Instituto Superior de Ciências da } \\
\text { Administração }\end{array}$ & \multicolumn{2}{|c|}{ Gestão Hoteleira } & $\mathrm{X}$ \\
\hline $\begin{array}{l}\text { Instituto Superior de Ciências Empresariais e } \\
\text { do Turismo }\end{array}$ & \multicolumn{2}{|c|}{ Turismo } & $\mathrm{X}$ \\
\hline Instituto Superior de Educação e Ciências & \multicolumn{2}{|c|}{ Gestão Hoteleira } & $\mathrm{X}$ \\
\hline Instituto Superior de Espinho & \multicolumn{2}{|c|}{ Gestão Hoteleira } & $\mathrm{X}$ \\
\hline Instituto Superior Politécnico do Oeste & \multicolumn{2}{|c|}{$\begin{array}{c}\text { Gestão de Empresas } \\
\text { Turísticas e Hoteleiras }\end{array}$} & $\begin{array}{l}\text { Sociologia e Antropologia } \\
\text { do Turismo } \\
\end{array}$ \\
\hline
\end{tabular}

Continua... 
Continuação...

\begin{tabular}{|c|c|c|}
\hline Instituto Superior de Tecnologias de Fafe & Turismo & $\bullet$ Sociologia do Turismo \\
\hline Instituto Superior Politécnico Gaya & Turismo & $\mathrm{X}$ \\
\hline ISLA - Vila Nova de Gaia & Turismo & $\mathrm{X}$ \\
\hline Instituto Superior de Línguas e & Gestão Hoteleira & $\mathrm{X}$ \\
Administração (ISLA) - Lisboa & Turismo & $\bullet$ Sociologia do Lazer e do \\
& Turismo & $\mathrm{X}$ \\
\hline Instituto Superior de Administração e Gestão & & Total: $\mathbf{1 2}$ \\
\cline { 2 - 3 } & Gestão Hoteleira & Total: $\mathbf{2 4}$ \\
\hline Total: 20 & &
\end{tabular}

Fonte: Elaboração Própria (Baseado na DGES, 2012).

No ensino superior privado, e dos 24 Cursos de Turismo e/ou Hotelaria em atividade (Quadro II), aferiu-se que a 'Sociologia do Turismo' surge como disciplina obrigatória em 12 Cursos. Todavia, a disciplina aparece de forma exclusiva somente em seis cursos. Nos outros casos, ela está associada ao lazer e à antropologia.

Como se pode verificar no Quadro I e II, a temática do lazer surge, em alguns casos, associada à 'Sociologia do Turismo'. Esta situação deve-se especialmente ao facto de alguns sociólogos considerarem que "a disciplina da Sociologia do Turismo deve ser contextualizada dentro da Sociologia do Lazer" (DANN; COHEN, 2001, p. 303). Aliás, na pesquisa efetuada, observou-se que a 'Sociologia do Lazer' surge como disciplina obrigatória em dois cursos de turismo e não a 'Sociologia do Turismo'.

Em alguns casos, a associação da Sociologia do Turismo à Antropologia deve-se ao facto de ambas abordarem algumas temáticas que são comuns às duas como, por exemplo, os impactos socioculturais do turismo ou o encontro entre turistas e anfitriões. Isto significa, de certa forma, que nos estudos do turismo, "os antropólogos e os sociólogos estão especialmente inclinados a minar o campo do outro" (NASH; SMITH, 1991, p. 13). A cooperação entre a Sociologia e a Antropologia nos estudos do turismo tem sido produtiva em algumas temáticas nas últimas décadas, mas esta aliança também "pode ameaçar e tornar-se demasiado óbvia e redutora" (DANN; PARRINELLO, 2009, p. 18).

Noutros casos, a Sociologia do Turismo aparece aliada à Economia. Refira-se que alguns dos primeiros estudos sociológicos sobre as questões do turismo foram realizados por economistas. Cite-se, a título de exemplo, a obra "Sociologia do Turismo. Para uma nova compreensão do lazer e das viagens", editada em 1984, pelo economista Jost Krippendorf. Para este autor, "se não existisse o turismo, cúmplice da 
evasão, seria necessário construir clínicas e sanatórios, onde o ser humano se recuperasse do cansaço quotidiano" (KRIPPENDORF, 1989, p. 18). O autor sublinha que o turismo funciona como uma terapia para a sociedade, como uma válvula que de certa forma procura manter o funcionamento do mundo de todos os dias. Ele exerce um efeito estabilizador sobre o indivíduo, a sociedade e a economia (KRIPPENDORF, 1989).

A comunidade académica sempre esteve indecisa em estabelecer uma ordem hierárquica entre as ciências sociais que se dedicavam ao estudo do turismo (MUÑOZ DE ESCALONA, 2007). De facto, o turismo é um fenómeno complexo e diversificado e, por isso, é abordado de acordo com as diversas visões dos autores. No que concerne aos estudos sociológicos e económicos do turismo, alguns autores consideram que a primeira ciência em termos hierárquicos é a Economia, enquanto outros realçam que é a Sociologia.

Para uns, a primeira é a Economia [...] Para outros, a ciência matriz do turismo é a Sociologia, mas a verdade é que esta ciência, que acredita que pode explicar a propensão que os seres humanos têm para se deslocar de um lugar para outro, não explica as razões que levam os empresários a satisfazer com bens e serviços as necessidades daqueles que se movem (MUÑOZ DE ESCALONA, 2007, p. 52-53).

Como já foi referido anteriormente, a Sociologia não pode reivindicar para si o monopólio do turismo. As funções que o turismo exerce sobre as diversas dimensões da sociedade implicam uma investigação interdisciplinar ou multidisciplinar que será compreendida em diferentes perspetivas e de acordo com cada disciplina.

$\mathrm{Na}$ recolha da informação, foi possível verificar que as áreas onde os cursos estão inseridos também têm influência sobre a designação da disciplina, bem como da sua existência ou inexistência. Por exemplo, o Curso 'Turismo, Lazer e Património', que está no Departamento de Geografia da Universidade de Coimbra, oferece a 'Sociologia do Turismo' como unidade curricular optativa e a 'Geografia do Lazer' como obrigatória. Por outro lado, e através da análise aos quadros, verifica-se que a maioria dos Cursos de Gestão Hoteleira não oferecem a unidade curricular 'Sociologia do Turismo’ como disciplina obrigatória.

Os objetivos gerais dos cursos e o perfil de saída podem também determinar a existência ou não da 'Sociologia do Turismo'. Outra questão que também pode 
influenciar é a formação académica dos docentes. Sublinhe-se que em Portugal, o único Curso que está num Departamento de Sociologia é o $1 .^{\circ}$ Ciclo de Estudos em Turismo da Universidade de Évora.

\section{CONCLUSÃO}

O turismo é um fenómeno social reconhecido, especialmente, por dois atores (turista e anfitrião) que desempenham papéis fundamentais dentro da atividade turística. Assim sendo, cabe à sociologia do turismo procurar compreender a natureza da interação entre os turistas e os anfitriões, bem como analisar os impactos sociais e culturais que o turismo provoca nas sociedades recetoras e emissoras (MARUJO, 2005).

$\mathrm{Na}$ análise ao quadro I e II, verificou-se que a disciplina da 'Sociologia do Turismo' existe apenas em 31 dos cursos em funcionamento, o que significa que em 29 dos cursos oferecidos ela não é relevante para os estudos do turismo. Por outro lado, e em alguns casos, ela surge associada à temática do lazer, da economia, da antropologia e da metodologia, o que revela uma certa crise de identidade.

O turismo, na atualidade, passou a assumir um papel de agente social, político e económico nas sociedades onde se desenvolve e, por isso, temas como a migração, o turismo familiar, o turismo religioso, os efeitos sociais do turismo nas sociedades recetoras, a interação social entre turistas e anfitriões, o turismo gay, o turismo acessível e o turismo sexual não devem ser ignorados nos estudos sociológicos. Se o turismo é um fenómeno social e se dentro de uma sociedade ele exerce um papel socializador, então, nos cursos superiores de turismo e áreas afins deve existir uma maior preocupação em incluir a disciplina da 'Sociologia do Turismo' nas estruturas curriculares.

Em estudos futuros deverão ser examinados os conteúdos programáticos da 'Sociologia do Turismo' que englobam os diferentes Cursos Superiores de Turismo (1. ${ }^{\circ}$ Ciclo de Estudos) em Portugal, bem como a importância que a Sociologia do Turismo assume para a investigação académica no país. 


\section{REFERÊNCIAS}

ANDRADE, N. los Orígenes de la sociología del turismo, sociología del deporte y sus vinculaciones con la sociología del medioambiental. Anuario de Estudios en Turismo - Investigación y Extensión, Neuquén, v. 10, p. 85-101, 2010.

APOSTOLOPOULOS, Y. Introduction: reinventing the sociology of tourism. In: APOSTOLOPOULOS, Y.; LEIVADI, S.; YIANNAKIS, A. (Eds.). The sociology of tourism. Theoretical and empirical investigations. London and New York: Routledge, 2001. p. 1-14.

ASCANIO, A. Turismo: La ciencia social de los viajes. Estudios y Perspectivas en Turismo, Buenos Aires, v. 1, n. 3, p. 185-197, 1992.

COHEN, E. Toward a Sociology of international tourism. Social Research, v. 39, n. 1, p. 164-182, 1972.

Rethinking the sociology of tourism. Annals of Tourism Research. v. 6, n. 1, p. 13-14, 1979.

. The Sociology of Tourism: approaches, issues, and findings. Review of Sociology, v. 10, p. 373-392, 1984.

. The sociology of tourism: approaches, issues, and findings. In: APOSTOLOPOULOS, Y.; LEIVADI, S.; YIANNAKIS, A. (Eds.). The sociology of tourism. Theoretical and empirical investigations. London and New York: Routledge, 2001. p. 51-71.

DAMIÁN, A. El turismo desde un enfoque de sociología constructivista. Teoría y Praxis, v. 6, p. 107-122, 2009.

DANN, G. Theoretical State-of-the-Art in the Sociology and Anthropology of Tourism. Tourism Analysis, v. 10, n. 1, p. 1-13, 2005.

DANN, G.; COHEN, E. Sociology and tourism. In: APOSTOLOPOULOS, Y.; LEIVADI, S.; YIANNAKIS, A. (Eds.), The sociology of tourism. Theoretical and empirical investigations. London and New York: Routledge, 2001. p. 301-314.

DANN, G.; PARRINELlO, G. The Sociology of Tourism European Origins and Developments. United Kingdom: Eemrald, 2009.

DIAS, R. Sociologia do Turismo. São Paulo: Atlas, 2003.

DURKHEIM, E. As regras do método sociológico. São Paulo: Ed. Nacional, 1990.

FRANKLIN, A. The Sociology of Tourism. In: JAMAL, T.; ROBINSON, M. (Eds.). The sage handbook of tourism studies. London: Sage Publications, 2009. p. 65-81. 
FUSTER, L. Teoría y técnica del turismo. Madrid: Editora Nacional, 1974.

GIDDENS, A. Sociologia. Lisboa: Fundação Calouste Gulbenkian, 2010.

GIL, A.; LUCAS, F.; CUEVA, M. Introducción. In: GIL, A. (Coord.), Sociología del turismo. Barcelona: Ariel, 2003. p. 17-22.

HUETE, R. Tourism Studies in Spain: the role of sociology in degree programmes. Journal of Teaching in Travel \& Tourism, v. 7, n. 2, p. 73-92, 2007.

JAFARI, J.; RITCHIE, B. Toward a Framework for tourism education: problems and prospects. Annals of Tourism Research. v. 8, n. 1, p. 13-34, 1981.

JENNINGS, G. Tourism research. (2. Ed.), Milton: John Wiley \& Sons Australia, 2010.

KRIPPENDORF, J. Sociologia do turismo. Para uma nova compreensão do lazer e das viagens. Rio de Janeiro: Civilização Brasileira, 1989.

Content analysis: an introduction to its methodology. London: Sage Publications, 2004.

LANFANT, M. Methodological and conceptual issues raised by the study of international tourism. A test for sociology. In: PEARCE, D.; BUTLER, R. (Eds.), Tourism research: critiques and challenges. London: Routledge, 1993. p. 70-87.

LANQUAR, R. Sociologie du tourisme et des voyages. Paris: Press Universitaires de France, 1985.

LICKORISH, L.; JENKINS, C. Una introducción al turismo. Madrid: Síntesis, 2000.

MACCANNELL, D. El turista: una nueva teoría de la clase ociosa. Madrid: Melusina, 2003.

MARUJO, M. A sociologia e o turismo. In: RAMOS, F.; DA SILVA, C. (Orgs.), Sociologia em Diálogo (2). Évora: Departamento de Sociologia da Universidade de Évora/CISA-AS. 2005. p. 21-32.

MAZÓN, T. Sociología del turismo. Madrid: Centro de Estudios Ramón Areces, 2001.

MOESCH, M. A produção do saber turístico. São Paulo: Contexto, 2002.

MUELA, G. La sociología del turismo como disciplina. In: GIL. A. (Coord.), Sociología del turismo. Barcelona: Ariel, 2003. p. 43-81.

MUÑOZ DE ESCALONA, F. El turismo explicado con claridad. 2007. Disponível em: <www.eumed.net/libros/2007c/310/>. Acesso em: 11/09/2012. 
NASH, D.; SMITH, V. Anthropology and Tourism, Annals of Tourism Research. v. 18, n. 1, p. $12-25,1991$.

SMITH, M.; MACLEOD, N.; ROBERTSON, M. Key concepts in tourist studies. London: Sage Publications, 2010.

TRIBE, J. Tribes, territories and networks in the tourism academy. Annals of Tourism Research. v. 37, n. 1, p. 7-33, 2010.

URRY, J. O olhar do turista: lazer e viagens nas sociedades contemporâneas. São Paulo: Studio Nobel, 1996.

URRY, J.; LARSEN, J. The tourist gaze 3.0. London: Sage Publications, 2011.

WEBER, M. Economia e Sociedade: fundamentos da sociologia compreensiva. Brasília: Universidade de Brasília, 1991.

Recebido em: 17-03-2013.

Aceito para publicação em: 16-04-2013. 